\title{
Wer kommunizieren kann, braucht weniger Antibiotika
}

Es ist unbestritten, dass bei respiratorischen Infekten, die meist viral bedingt sind, zu häufig Antibiotika verordnet werden. Jetzt konnte eine Studie zeigen, dass der CRP-Wert und ein Kommunikationstraining helfen, die Anzahl unnötiger Antibiotikabehandlungen zu reduzieren.

— Eingeschlossen in die Studie wurden 431 Patienten mit einer Infektion der unteren Atemwege. Bei der Hälfte der betroffenen Patienten wurde vor der Antibiotikaverordnung der CRP-Wert bestimmt. Außerdem erhielt die Hälfte der verordnenden Ärzte ein intensives Kommunikationstraining.

Bei Patienten mit CRP-Test wurde in $31 \%$ ein Antibiotikum verschrieben, bei Patienten ohne Berücksichtigung des CRP-Wertes dagegen in $53 \%$ der
Fälle. Noch größer war der Unterschied im Hinblick auf das Kommunikationstraining. Ärzte mit einem solchen verordneten bei $27 \%$ der Patienten ein Antibiotikum, ohne ein solches Training dagegen bei 54\% der Patienten. Wurden CRP-Wert und Kommunikationstraining eingesetzt, so reduzierte sich die Verschreibungshäufigkeit sogar auf 23\%. Diese Vorgehensweise hatte keinerlei Einfluss auf die Genesungszeit und die Zufriedenheit des Patienten.

\section{Kommentar}

Die Verordnung von Antibiotika bei respiratorischen Infekten ist ein leidiges Thema. Auch wenn wir Ärzte wissen, dass eine antibiotische Therapie nur dann sinnvoll ist, wenn Klinik und Laborbefund für einen bakteriellen Infekt sprechen, lassen sich viele im praktischen Alltag doch zu einer Verordnung eines Antibiotikums hinreißen, insbesondere wenn der Patient oder Angehörige dies eindringlich wünschen. Gerade bei Kindern wird von Seiten der Eltern nicht selten „starker Druck" auf den Arzt ausgeübt. Sich diesen unberechtigten Forderungen zu entziehen, ist sicherlich nicht immer einfach. Dies erfordert eine besondere Fähigkeit der Kommunikation. Doch wer sollte eine solche vermitteln? Dies könnte nur im Rahmen von Qualitätszirkeln, wie sie die Kassenärztlichen Vereinigungen anbieten, trainiert werden. .

P. StiefelHAGEN .

\begin{abstract}
J. W. Cals et al.
Effect of point of care test $C$ reactive protein and training in communication skills on antibiotic use in lower respiratory infections: cluster randomised trial. Brit. Med. J. 338 (2009) 1112-1116
\end{abstract}

\section{Frauen helfen Männern beim Abnehmen}

\begin{abstract}
Wie sich der Lebensstil bei Männern ändert, wenn ihre Frauen abnehmen, zeigt eine japanische Studie.
\end{abstract}

- 104 Männer mit abdominaler Adipositas und 36 Frauen wurden für die Studie gewonnen. Die Frauen mussten nicht übergewichtig sein, jedoch ihre Ehe-

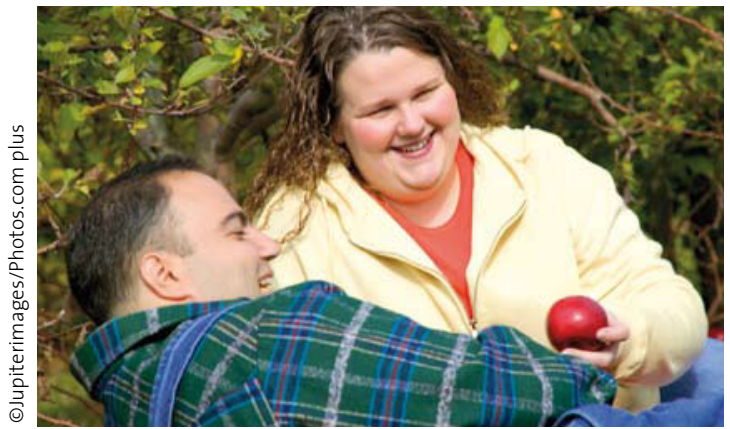

Eva mit dem Apfel - nicht immmer ein Sündenfall. männer. Die Teilnehmer waren im Durchschnitt 52 Jahre alt, die Männer hatten einen BMI von $27 \mathrm{~kg} /$ $\mathrm{m}^{2}$ und die Frauen von $24 \mathrm{~kg} / \mathrm{m}^{2}$. Bei den Männern wurden drei Gruppen gebildet: direkte, indirekte (= Intervention bei Frauen) und keine Intervention.

Die Intervention betraf vor allem die Ernährung bzw. die Gewichtsreduktion. Die Teilnehmer wurden hinsichtlich der Reduktion von Kohlenhydraten und Fett theoretisch und praktisch (Einkauf- und Kochkurse) instruiert, und sie führten ein Ernährungstagebuch.

Nach 14 Wochen bewirkte die Intervention bei den Männern eine Gewichtsabnahme von $6,2 \mathrm{~kg}$ und bei den Frauen von 5,9 kg. War nur bei den Frauen interveniert worden, nahmen die Ehemänner auch $\mathrm{ab}$, und zwar um 4,4 kg.

Die Zahl der Diagnosen „metabolisches Syndrom“ verringerte sich bei den Männern mit direkter Intervention von 18 auf sechs Fälle und bei Männern mit indirekter Intervention von 17 auf acht Fälle. Auch diesbezüglich bestand eine signifikante Korrelation zwischen Männern mit indirekter Intervention und den Ehefrauen $(r=0,54)$.

\section{Kommentar}

Die Beobachtung, dass Männer allein aufgrund der Tatsache, dass ihre Ehefrauen an einem Programm teilnehmen, ebenfalls Gewicht und Körperfett verlieren und Komponenten des metabolischen Syndroms zurückdrängen, ist beachtenswert. Andererseits verwundert das Studienergebnis nicht, betrachtet man die klassische Rolle der Frau in Familie und Partnerschaft. Die Kompetenz hinsichtlich der Ernährung liegt in vielen Paarbeziehungen bei der Frau.

A. WIRTH =

\section{- T. Matso et al.}

Indirect lifestyle intervention through wives improves metabolic syndrome components in men. Intern. J. Obes. 34 (2010) 136-145 